\title{
Rare earth doped cobalt aluminate blue as an environmentally benign colorant
}

\author{
Sri Parasara RADHIKA, Kalarical Janardhanan SREERAM*, \\ Balachandran Unni NAIR \\ Chemical Laboratory, Central Leather Research Institute, Council of Scientific and Industrial \\ Research, Adyar, Chennai 600020, India
}

Received: September 28, 2012; Revised: November 19, 2012; Accepted: November 21, 2012

(CThe Author(s) 2012. This article is published with open access at Springerlink.com

\begin{abstract}
Increasing energy cost calls for exterior coatings with high near infra-red reflectance, so as to reduce heat absorption and in turn cost of air-conditioning. While modulations of substrate, use of white metal oxides as pigments or under-layers has been reported in past, reports on metal oxide or doped metal oxide pigments with high NIR reflectance is scarce. We report for the first time a blue colored cobalt aluminate type pigment prepared through doping of cerium, praseodymium or neodymium. CIELAB color measurements and calculation of $\Delta E$ indicated that the $\mathrm{Nd}$ doped sample had crystal size of $(36 \pm 1) \mathrm{nm}$, bandgap value of $(2.4 \pm 0.2) \mathrm{eV}$ and color coordinates similar to that of cobalt aluminate. The molar ratio as estimated by EDX was found to be $\mathrm{Al}: \mathrm{Cu}: \mathrm{Co}: \mathrm{Ce}: \mathrm{Nd}: \mathrm{O}=$ $2: 0.06: 0.06: 0.012: 0.00012: 6.18$. The pigment was found to have potential applications as a cool blue colorant, owing to changes in optical properties arising out of crystal chemistry changes. Incorporation of rare earth metal ions was found to enhance the NIR reflectance by $10 \%$, when compared to a conventional cobalt aluminate pigment. The oxide has been well characterized and its performance as a pigment evaluated. We have proposed that changes in crystal lattice when neodymium enters into $\mathrm{Ce}^{4+}$ sites enhance the NIR reflectance by about $9 \%$ as against the entry of praseodymium.
\end{abstract}

Key words: optical materials; oxides; chemical synthesis; environmental coatings; color centers; crystal structure; defects

\section{Introduction}

Materials with high near infra-red (NIR) reflectance can be produced by a reflective metal substrate, NIR

\footnotetext{
* Corresponding author.

E-mail: kjsreeram@clri.res.in
}

reflective under-layer and/or pigments with high scattering in NIR region. With applications in military, construction, plastic, leather and ink industries, near infra-red reflective non-white pigments are becoming more and more relevant [1-5]. They are expected to reflect almost $49 \%$ of near-infrared radiation from the sun $(\lambda=750-2500 \mathrm{~nm})$ and thus reduce energy requirements for cooling of interiors of buildings, automobiles, etc [6]. They also have applications such 
as camouflage pigments for military uniforms, IR reflective polymeric screens for green houses, etc [7]. While these pigments can be both inorganic and organic in character, the metal oxide based inorganic pigments are particularly useful as visual camouflages and exterior surface coatings. Several authors have provided detailed description of pigments useful in NIR reflective coatings. Morphology, chemical composition and changes to optical properties due to particle size have been reported to influence the NIR reflective properties of pigments [7]. The refractive index, which in turn depends on the electronic structure of the metal in the metal oxide, also plays an important role in determining the NIR properties [7].

Some of the pigments or pigment formulations reported as useful in NIR reflective coatings such as the azo pigments and those containing $\mathrm{Cr}(\mathrm{VI})$ and cadmium are today a subject of eco-bans and need to be phased out [6]. Amongst the various colors, the blue colored pigments have attracted much attention. Cobalt blue $\left(\mathrm{CoAl}_{2} \mathrm{O}_{4}\right)$, Cerulean blue $\left(\mathrm{CoO} \cdot \mathrm{SnO}_{2}\right)$, ultramarine $\left(\mathrm{Na}_{7} \mathrm{Al}_{6} \mathrm{Si}_{6} \mathrm{O}_{24} \mathrm{~S}_{3}\right)$, Prussian blue $\left(\mathrm{Fe}_{4}\left[\mathrm{Fe}(\mathrm{CN})_{6}\right]_{3}\right)$, and azurite $\left[\mathrm{Cu}_{3}\left(\mathrm{CO}_{3}\right)_{2}(\mathrm{OH})_{2}\right]$ need replacement in modern context due to their low durability, poor stability and low level of environmental acceptability. The paucity of blue/green inorganic solids that are color-stable, environmentally benign and cost effective has aroused interest amongst researchers.

Introduction of $\mathrm{Mn}^{3+}$ into the trigonal bipyrimidal sites of metal oxides has been reported to provide for intense blue color. By substituting $\mathrm{Mn}^{3+}$ for $\mathrm{In}^{3+}$ in hexagonal $\mathrm{YInO}_{3}$, highly stable blue inorganic pigments have been recently reported [8]. Manganese in its $5+$ oxidation state, in combination with $\mathrm{Ba}$ is also a blue colorant [9]. However, barium is currently associated with toxicity. As the size of the pigment reduced to the nanoregime, such as in the case of $\mathrm{Co}_{x} \mathrm{Zr}_{1-x} \mathrm{Al}_{2} \mathrm{O}_{4}$, a blue colored pigment which is environmentally benign can be obtained [10]. In the class of environmentally benign pigments, the lanthanide based pigments are increasingly been reported as viable alternatives to transition metal oxide based pigments in both high and low temperature applications owing to their higher biocompatibility. They also have applications in phosphorescence, luminescence, etc [11]. Doping of cerium in $\mathrm{MnF}_{2}$ nano crystals has been reported to have enhanced luminescence [12]. $\mathrm{LaAlGe}_{2} \mathrm{O}_{7}$ doped with $\mathrm{Gd}^{3+}$ and
$\mathrm{Tb}^{2+}$ has been reported as very promising phosphor [13]. The novel phosphors of the type $\mathrm{Li}_{0.05} \mathrm{Eu}_{0.05} \mathrm{La}_{0.9} \mathrm{PO}_{4}$ has also been reported recently [14]. Wide range of colors has been obtained by modulating the band gap of the pigments through appropriate doping with transition metal ions and use of mineralizers [15]. For instance, yellow-green pigments are obtained when molybdenum is doped on to praseodymium, while the replacement of molybdenum with calcium results in green color. A combination of cerium, titanium and praseodymium provides a red color, the replacement of titanium with tungsten in the composition provides for red-yellow and replacement of titanium with iron provides for brown color. Addition of phosphate flux to the combination results in change of hue. In general, solid state reactions in the temperature range of $1300-1600{ }^{\circ} \mathrm{C}$ have been employed when the host lattice is a rare earth oxide. Rare earth cuprates, where $\mathrm{RE}=\mathrm{Dy}$ or $\mathrm{Y}$ has been reported as blue colored pigments [16]. The added advantage of several rare earth based pigments reported in the color range of yellow to brown is the high NIR solar reflectance [17].

Cobalt-blue $\left(\mathrm{CoAl}_{2} \mathrm{O}_{4}\right.$ - Thenard's blue $)$ is an inorganic pigment with a blue-hue and spinal structure. $\mathrm{CoAl}_{2} \mathrm{O}_{4}$ is also known to exhibit high chemical stability and is insoluble in acids. This makes it an attractive candidate for applications in optical, dielectric and sensing applications [18]. Conventional methods of appending oxide spinels into ceramics usually involve high temperature sintering processes, where in volatilization of metal ions and subsequent environmental problems have been reported [19].

In the present work, we report a comprehensive study on the influence of rare earth doping on cobalt aluminate, synthesized by solid-state calcination reaction from water soluble metal salts of aluminium, cobalt and copper, in the absence and presence of rare earth metal ions such as $\mathrm{Ce}$, Pr and Nd. Methods such as X-ray diffraction (XRD), scanning electron microscopy (SEM), photon correlation spectroscopy, diffuse reflectance and NIR spectroscopy have been employed for to understand the influence of rare earth metal ions on the NIR properties of the generated oxides. The ability of these oxides to disperse well into matrices such as PMMA (for plastics) and linseed oil (for surface coatings) and thus uniformly coat the surfaces was also analyzed. 


\section{Experiment}

\subsection{Preparation}

Rare earth doped cobalt aluminate was prepared from ACS grade aluminium(III) sulfate octadecahydrate ( $>98 \%$ purity) and cobalt(II) chloride hexahydrate ( $>98 \%$ purity). Rare earth salts employed for doping were cerium(III) chloride heptahydrate (99.9\% purity), praseodymium(III) carbonate $(99.9 \%$ purity) and neodymium(III) chloride ( $99.9 \%$ purity). A small quantity of copper(II) sulfate ( $99 \%$ purity) was incorporated for optimizing the color. The metal salts taken in appropriate quantities so as to obtain a mole ratio of $\mathrm{Al}: \mathrm{Cu}: \mathrm{Co}=2.0: 0.2: 0.2$ was employed in this study as the source for the transition metal oxide. Rare earth metal ions were doped into the lattices, such that a mole ratio of $\mathrm{Al}: \mathrm{Cu}: \mathrm{Co}: \mathrm{Ce}$ was $2.0: 0.2: 0.2: 0.2$ and $\mathrm{Al}: \mathrm{Cu}: \mathrm{Co}: \mathrm{Ce}: \mathrm{Pr} / \mathrm{Nd}$ was $2.0: 0.2: 0.2: 0.15: 0.05$. The well homogenized mixture (thorough mixing using a mortar and pestle) was calcined in an electrically heated furnace (chamber $-w \times h \times d=150 \mathrm{~mm} \times 150 \mathrm{~mm} \times 200 \mathrm{~mm}$ ) at $1000{ }^{\circ} \mathrm{C}$ for a duration of $2 \mathrm{~h}$. The rate of heating up to $250{ }^{\circ} \mathrm{C}$ was maintained at $15{ }^{\circ} \mathrm{C} / \mathrm{min}$ and subsequently reduced to $5^{\circ} \mathrm{C} / \mathrm{min}$. The obtained powder was cooled naturally, homogenized in a mortar with a pestle and characterized.

\subsection{Characterization}

Dynamic light scattering (DLS) was performed on a Malvern Instruments Zeta Sizer 3000 HSA, using a $\mathrm{He}-\mathrm{Ne}$ laser $(633 \mathrm{~nm})$, at a scattering angle of $90^{\circ}$ and at $(25 \pm 1){ }^{\circ} \mathrm{C}$. The mean hydrodynamic diameter of the particles was determined using the software provided by Malvern Instruments. The NNLS (Non-negative least square routine) model was applied to obtain the size data. All autocorrelation function fits were checked and found to be in accordance with the experimental data. All measurements were obtained from the mean of diluted samples (10 $\mathrm{mg}$ of dispersion in $10 \mathrm{~mL}$ of distilled water). The accuracy was $\pm 10 \mathrm{~nm}$.

The XRD measurements were carried out using an Rigaku Miniflex (II) desktop diffractometer (Ni filtered $\mathrm{CuK} \alpha$ radiation with $\lambda=0.154060 \mathrm{~nm}$ ) in the $2 \theta$ angle range $10^{\circ}-80^{\circ}$ with step of $0.1^{\circ}$. XRD patterns were compared with the ICSD reference data for phase identification. Average sizes of coherently scattering domain $D_{\text {XRD }}$ were calculated by the line broadening analysis using (101) or (111) diffraction maxima according to the Scherer equation

$$
D_{\text {XRD }}=\frac{0.94 \lambda}{f w h m \cos (\theta)}
$$

where fwhm is the full width at half-maximum corrected on the instrumental broadening.

The scanning electron microscopy (SEM) analysis of the samples was performed in a Jeol JSM 5600-LV microscope. For this, samples were placed on a double sided sticky carbon tape mounted on aluminium sample holders and then sputter coated with gold film. UV-vis diffuse reflectance spectra (UV-vis DRS) were recorded in the absorbance mode at room temperature in the range of 380-780 $\mathrm{nm}$ on a Shimadzu (UV-2450) double-beam spectrophotometer equipped with integrating sphere attachment (ISR 2200) using $\mathrm{BaSO}_{4}$ as the reference. The instrument was interfaced with a computer for data collection and analysis. For the measurements, the powder samples were filled in a hole of a sample holder and the surface smoothed. The layer can be regarded as infinitely thick, as required by Kubelka-Munk theory. According to Kortum, the absolute reflectance $\left(R_{\infty}\right)$ of an infinitely thick layer must be used to calculate Kubelka-Munk spectra [17].

$$
F\left(R_{\infty}\right) \equiv \frac{\left(1-R_{\infty}\right)^{2}}{2 R_{\infty}} \equiv \frac{K}{S} \approx c
$$

where $K$ and $S$ are the effective absorption and scattering coefficients. According to the theory, $F(R)$ is proportional to the concentration $c$ of the absorbing species as long as the assumption of absorbance of sample is not too high is fulfilled. The energy band gaps of the samples can be estimated from the tangent lines in the plot of the square root of Kubelka-Munk functions $F(R)$ against photo energy [20]. The tangent lines were extrapolated to $F(R)^{1 / 2}=0$. Color analyses were carried out following the CIE (Commission Internationale de L'Eclairage) recommendations and using the visible spectrum obtained from $380-780 \mathrm{~nm}$ (Shimadzu UV-2450 spectrophotometer, UVPC color analysis personal spectroscopy software V3). In this work, the CIELAB uniform space colorimetric parameters have been considered: rectangular coordinates $L^{*}$ (black-white component, lightness), $a^{*}$ and $b^{*}$ (chromatic coordinates representing red-green and yellow-blue axes, respectively), and the cylindrical coordinates $C_{a b}^{*}$ (chroma) and $h_{a b}$ (hue). These parameters were measured using as reference the CIE 1964 Standard Observer ( $10^{\circ}$ visual field) and 
the CIE standard illuminant D65. $\Delta E$, the color difference was computed as

$$
\Delta E=\sqrt{\left(L_{1}-L_{2}\right)^{2}+\left(a_{1}-a_{2}\right)^{2}+\left(b_{1}-b_{2}\right)^{2}}
$$

A Shimadzu UV-3600 UV-vis-NIR spectrophotometer along with a diffuse reflectance accessory (DRA) was used to measure reflectance properties of the pigments. The DRA was capable of measuring reflectance in the region of $250-2500 \mathrm{~nm}$; in the present study, the DRA was operated in the diffuse reflectance mode in the region of $700-2500 \mathrm{~nm}$, at $5 \mathrm{~nm}$ interval. The reflectance was measured as relative, defined as the ratio of flux reflected by the specimen to the flux reflected by a reference surface. Polytetrfluoroethylene (PTFE) was used as the reference. NIR solar reflectance $\left(R^{*}\right)$ was calculated in accordance with ASTM standard E891-87 [1,4,17]. Solar reflectance or fraction of solar radiation incident at wavelengths between $700-2500 \mathrm{~nm}$ is the irradiance weighted average of spectral reflectance, $r(\lambda)$, determined as

$$
R^{*}=\int_{700}^{2500} \frac{r(\lambda) i(\lambda) \mathrm{d}(\lambda)}{i(\lambda) \mathrm{d}(\lambda)}
$$

where $r(\lambda)$ is the spectral reflectance $\left(\mathrm{W} \cdot \mathrm{m}^{-2}\right)$ obtained from the experiment and $i(\lambda)$ is the solar spectral irradiance $\left(\mathrm{W} \cdot \mathrm{m}^{-2} \cdot \mathrm{nm}^{-1}\right)$ obtained from ASTM standard E891-87. The ability of the pigments to disperse well into long oil alkyd medium and function as a constituent of surface coatings was evaluated by the conventional determination of mass tone. Coloring performance in polymeric substrates was evaluated by $5 \% \mathrm{wt} / \mathrm{wt}$ addition onto poly (methyl methacrylate) (Sigma Aldrich) in the presence of acrolein and subsequent thermosetting of the polymer in cylindrical molds [21].

\section{Results and discussion}

Our investigations were initially focused on establishing the appropriate reaction conditions that produced the most intense blue color for cobalt aluminate. This was accomplished through a series of studies focusing on individual components of the reaction system such as mole ratio of $\mathrm{Al}, \mathrm{Co}$ and $\mathrm{Cu}$, the conditions for homogenization, temperature of calcination, rate of heating, dwell time and rate of cooling. The optimized conditions $(\mathrm{Al}: \mathrm{Cu}: \mathrm{Co}=$ $2.0: 0.2: 0.2, \quad T_{\text {reac }}=1000{ }^{\circ} \mathrm{C}, t_{\text {dwell }}=120 \mathrm{~min}, \quad r_{\text {heat }}=$
$5{ }^{\circ} \mathrm{C} / \mathrm{min}$ and $r_{\text {cool }}=5{ }^{\circ} \mathrm{C} / \mathrm{min}$ ) have been employed in all the studies reported in this work as baseline. The XRD pattern of the colorant oxide with and without $\mathrm{Ce}$ and $\mathrm{Pr} / \mathrm{Nd}$ doping is given in Fig. 1. In the absence of doping, (Fig. 1(a)) at the calcination temperature of $1000{ }^{\circ} \mathrm{C}$, the only crystalline phase that appeared was $\mathrm{CoAl}_{2} \mathrm{O}_{4}$ spinel, whose diffraction pattern matched with that of JCPDS file No. 82-2252 (spinel cubic $\mathrm{Fd} 3 \mathrm{~m}$, lattice size of $8.104 \AA$ ). The formation of $\mathrm{CoAl}_{2} \mathrm{O}_{4}$ like structures has been reported earlier from the direct interaction of Co with alumina to form the precursor of $\mathrm{CoAl}_{2} \mathrm{O}_{4}$ [18]. Copper added to the reaction mixture did not appear as a separate crystalline $\mathrm{CuO}$ phase, instead interacted with the

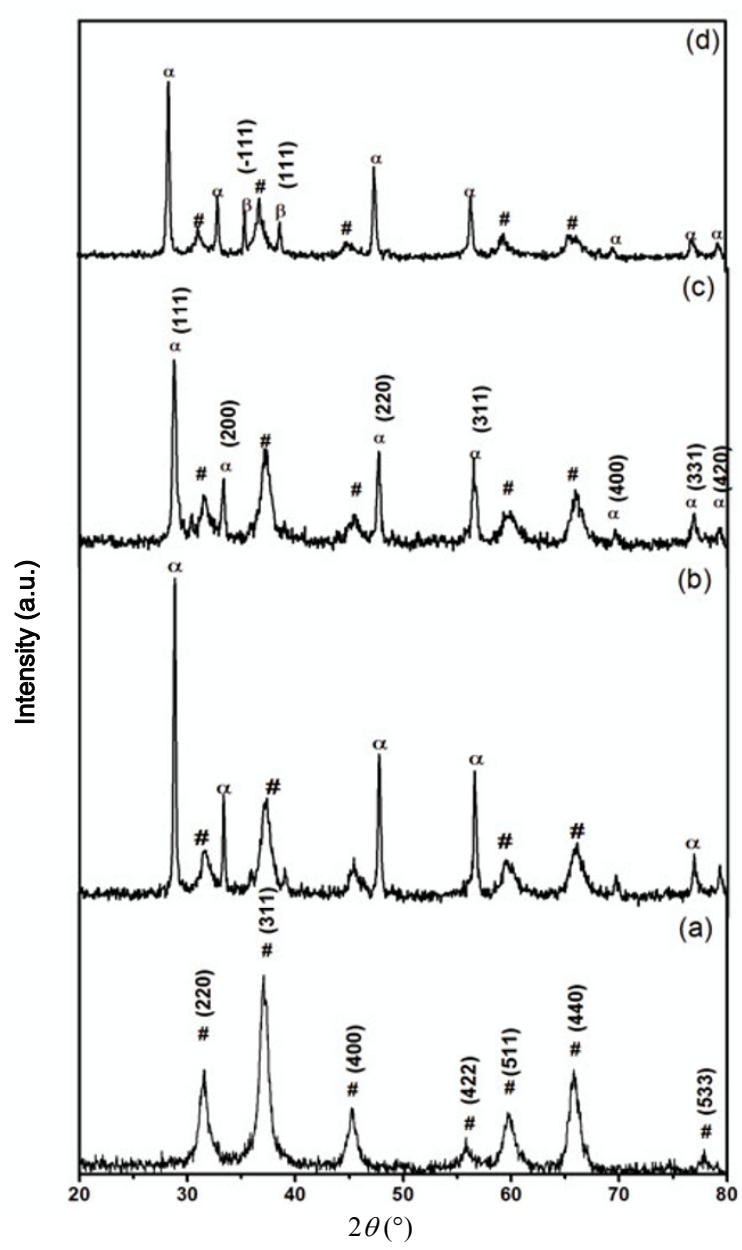

Fig. 1 Powder X-ray diffractograms of oxides of (a) $\mathrm{Al}, \mathrm{Cu}, \mathrm{Co}(2: 0.2: 0.2)$; (b) $\mathrm{Al}, \mathrm{Cu}, \mathrm{Co}, \mathrm{Ce}$ $(2: 0.2: 0.2: 0.15) ; \quad$ (c) $\mathrm{Al}, \mathrm{Cu}, \mathrm{Co}, \mathrm{Ce}, \mathrm{Pr}$ $(2: 0.2: 0.2: 0.15: 0.05)$ and (d) $\mathrm{Al}, \mathrm{Cu}, \mathrm{Co}, \mathrm{Ce}, \mathrm{Nd}$ $(2: 0.2: 0.2: 0.15: 0.05)$. Diffractogram (a) matched with JCPDS file No. 82-2252. 
precursor of $\mathrm{CoAl}_{2} \mathrm{O}_{4}$ to form the mixed spinel cubic $\mathrm{Cu}_{x} \mathrm{Co}_{1-x} \mathrm{Al}_{2} \mathrm{O}_{4}$, whose lattice parameters were similar to that of $\mathrm{CoAl}_{2} \mathrm{O}_{4}$. Further the relative intensities of XRD reflections $\left(I_{220} / I_{311}=0.6\right)$ in the blue pigment confirms the existence of $\mathrm{CoAl}_{2} \mathrm{O}_{4}$. The XRD patterns in (b), (c) and (d) compositions do contain reflections due to cobalt aluminate. However, in addition to cobalt aluminate the other phases are present as mentioned in Fig. 1. The other phases are $\mathrm{CeO}_{2}$ (marked as $\alpha$ ) and $\mathrm{CuO}$ depending on the starting compositions. Thus, other than composition (a), all the other compositions have more than one phase and from the intensities of the broad reflections, it appears that $\mathrm{CeO}_{2}$ (JCPDS file No. 43-1002) is the major phase.

The crystal size estimated from the most intense peak (311) in the case of Fig. 1(a) and (111) for Figs. 1(b)-1(d) varied as (39 \pm 2$),(46 \pm 1),(41 \pm 2)$ and $(36 \pm$ 1) $\mathrm{nm}$ for $\mathrm{Al}: \mathrm{Cu}: \mathrm{Co}, \mathrm{Al}: \mathrm{Cu}: \mathrm{Co}: \mathrm{Ce}, \mathrm{Al}: \mathrm{Cu}: \mathrm{Co}:$ $\mathrm{Ce}: \mathrm{Pr}$ and $\mathrm{Al}: \mathrm{Cu}: \mathrm{Co}: \mathrm{Ce}: \mathrm{Nd}$ respectively. The hydrodynamic diameter varied as 1224, 1622, 890 and $822 \mathrm{~nm}$ respectively. It can be seen that the introduction of $\mathrm{Ce}$ and $\mathrm{Nd}$ into the lattice in the place of $\mathrm{Ce}$ and Pr, provided for a reduction in crystal and particle size. Scanning electron microscopy provided information to substantiate the claim on particle size (Fig. 2(a)). The SEM image of the sample with $\mathrm{Nd}$ doping ( $\mathrm{Al}: \mathrm{Cu}: \mathrm{Co}: \mathrm{Ce}: \mathrm{Nd}=2.0: 0.2: 0.2: 0.15: 0.05)$ showed morphological and size homogeneity. The grain size was around $34-53 \mathrm{~nm}$. Energy dispersive X-ray diffraction analysis (Fig. 2(b)) confirmed the presence of the rare earth metal ions. The corresponding mole ratio was found to be $\mathrm{Al}: \mathrm{Cu}$ : $\mathrm{Co}: \mathrm{Ce}: \mathrm{Nd}: \mathrm{O}=2: 0.06: 0.06: 0.012: 0.0001: 6.18$. A variation from the initial mole ratio could be attributed to the losses during homogenization or during calcination reactions.

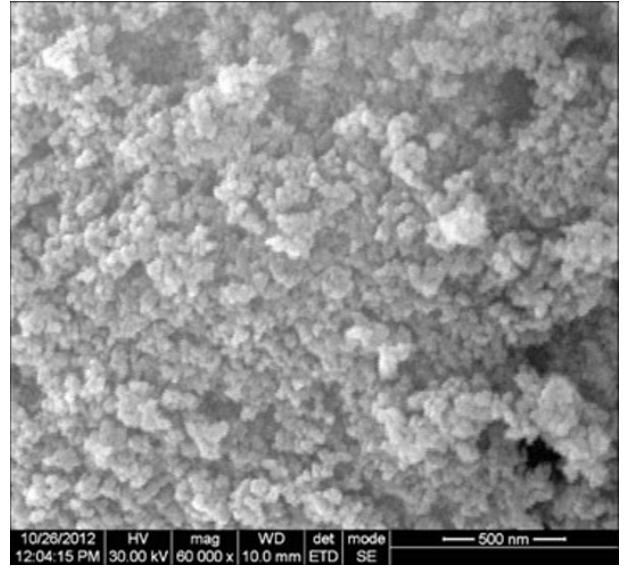

(a)

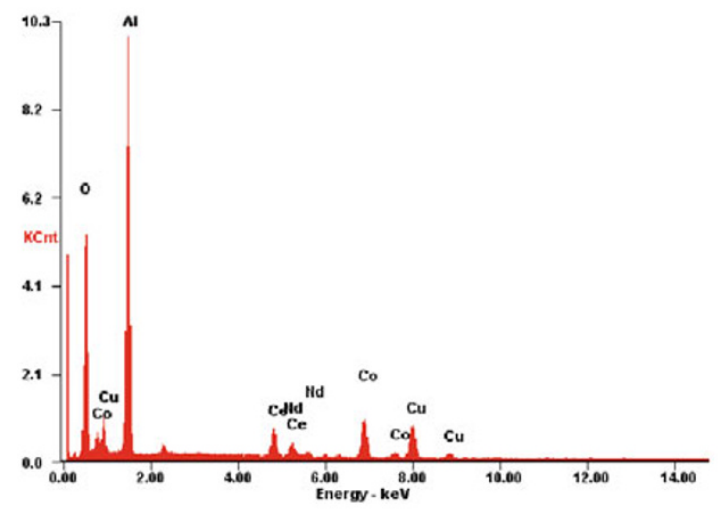

(b)

Fig. 2 (a) Scanning electron microscopic image of oxide of $\mathrm{Al}, \mathrm{Cu}, \mathrm{Co}, \mathrm{Ce}, \mathrm{Nd}$; (b) Corresponding EDX spectra.

The onset of optical absorption in cobalt aluminate occur around $2 \mathrm{eV}$, with shifts observed with preparatory conditions. Characteristic absorptions at $543 \mathrm{~nm}, 578 \mathrm{~nm}$ and $627 \mathrm{~nm}$, typical of $\mathrm{Co}^{2+}$ ions present in a $T_{\mathrm{d}}$ ligand field with $3 \mathrm{~d}^{7}$ configuration were observed in the case of cobalt aluminate (Fig. 3). According to literature, the triple band is attributed to

Table 1 The Color coordinates and band gap energy for cool blue pigment

\begin{tabular}{|c|c|c|c|c|c|c|}
\hline \multirow{2}{*}{ Composition } & \multicolumn{5}{|c|}{ Color coordinates } & \multirow{2}{*}{$\begin{array}{c}\text { Band gap energy } \\
(\mathrm{eV})\end{array}$} \\
\hline & $L^{*}$ & $a^{*}$ & $b^{*}$ & $h^{\circ}$ & $c$ & \\
\hline $\begin{array}{l}\mathrm{Al}:: \mathrm{Cu}: \mathrm{Co} \\
2: 0.2: 0.2\end{array}$ & 35.82 & -6.80 & -20.28 & 252.27 & 22.34 & 2.39 \\
\hline $\begin{array}{l}\mathrm{Al}: \mathrm{Cu}: \mathrm{Co}: \mathrm{Ce} \\
2: 0.2: 0.2: 0.15\end{array}$ & 42.16 & -6.65 & -14.71 & 245.68 & 16.14 & 2.43 \\
\hline $\begin{array}{l}\mathrm{Al}: \mathrm{Cu}: \mathrm{Co}: \mathrm{Ce}: \mathrm{Pr} \\
2: 0.2: 0.2: 0.15: 0.05\end{array}$ & 49.28 & -9.24 & -18.24 & 243.13 & 20.44 & 2.42 \\
\hline $\begin{array}{l}\mathrm{Al}: \mathrm{Cu}: \mathrm{Co}: \mathrm{Ce}: \mathrm{Nd} \\
2: 0.2: 0.2: 0.15: 0.05\end{array}$ & 42.69 & -8.49 & -21.29 & 247.29 & 21.99 & 2.41 \\
\hline
\end{tabular}




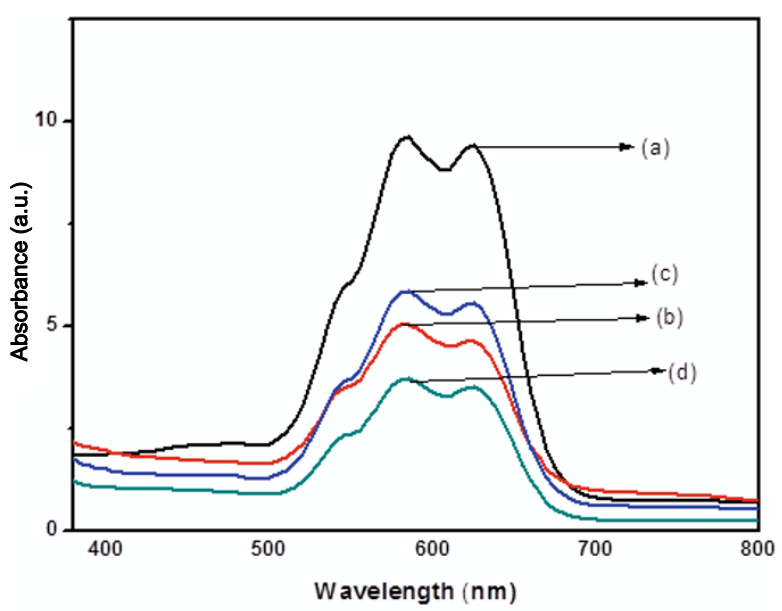

Fig. 3 Absorbance spectra of oxides of (a) $\mathrm{Al}, \mathrm{Cu}$, $\mathrm{Co}$; (b) $\mathrm{Al}, \mathrm{Cu}, \mathrm{Co}, \mathrm{Ce}$; (c) $\mathrm{Al}, \mathrm{Cu}, \mathrm{Co}, \mathrm{Ce}, \mathrm{Pr}$ and (d) $\mathrm{Al}, \mathrm{Cu}, \mathrm{Co}, \mathrm{Ce}, \mathrm{Nd}$.

${ }^{4} \mathrm{~A}_{2}(\mathrm{~F}) \rightarrow{ }^{4} \mathrm{~T}_{1}(\mathrm{P})$ transitions arising from Jahn-Teller distortion of $T_{\mathrm{d}}$ structure [22]. No change in the spectral features was observed by the addition of $\mathrm{Ce}$ and $\mathrm{Pr} / \mathrm{Nd}$. Cerium and praseodymium will be in the $4+$ oxidation state and hence absorbance in visible region will be absent. $\mathrm{Cu}^{2+}$ and $\mathrm{Nd}^{2+}$ are expected to have absorbance in the visible region. However, due to small concentration employed and thus present in the matrix, a significant absorbance is not detected. No major changes were also observed in the band gap energy which remain at around $(2.4 \pm 0.2) \mathrm{eV}$ in all the cases, indicating that a major shift in the color of the pigments on doping is not likely. This is in tune with the earlier reports that the density of localized states in the band gap is lesser at higher temperatures of annealing due to structural defects [23]. All samples were blue (Table 1) with a luminosity $\left(L^{*}\right)$ value ranging from 35 to 49 , while $a^{*}$ and $b^{*}$ values were between -6.5 to -9.5 and -14.5 to -21.5 respectively. A slight positive shift in $b^{*}$ values when Ce and Pr are doped into cobalt aluminate is an indication of yellowness. CIELAB based color difference $(\Delta E)$ between undoped and doped sample was the lowest with $\mathrm{Nd}$ doping.

A pigment when exposed to light is expected to absorb, transmit or reflect the radiation. NIR radiations in the wavelength region $\sim 1500 \mathrm{~nm}$ is too low to cause a promotion of the electrons from one bonding state to the other, resulting in low or no absorption of light in this region. The resultant beam which falls on the pigment will then be refracted, reflected or scattered, depending on the refractive index of the material. For a given value of $L^{*}$, white has the greatest degree of reflectance and absorption effect in the visible region of light. Pigments possessing low absorbance in the NIR region can be considered as ideal for cool coatings, provided the background or the material on which coated is NIR reflective [2]. For instance, cobalt aluminate (absorption coefficient, $K \sim 150 \mathrm{~mm}^{-1}$, backscattering coefficient, $S \sim 30 \mathrm{~mm}^{-1}$ ) has been reported to have undesirable absorption and weak NIR scattering in the $1200-1600 \mathrm{~nm}$ range [6]. To obtain cool coating features, cobalt aluminate needs to be coated on NIR reflective substrates such as white, which makes the color lighter [1]. Further, such white backgrounds are rarely observed in the case of roof surfaces, leather etc. From Fig. 4, it can be seen that the NIR solar reflectance $\left(R^{*}\right)$ of undoped cobalt aluminate was $29 \%$, similar to the case of Pigment blue 36 (cobalt chromite blue), which had a value of $30 \%$. Nd doped sample prepared in this study had an $R^{*}$ value of $(39 \pm 1) \%$ in the wavelength region of 1100 $\mathrm{nm}$. This observation indicates that rare earth doped oxide serves as a potential candidate for cool pigments. The changes in the NIR reflectance spectra and the solar reflectance $\left(R^{*}\right)$ values when $\mathrm{Nd}$ is doped in the place of $\mathrm{Pr}$ in the cobalt aluminate lattice needs to be analyzed on the base of particle size of the final product and the refractive index of the material. Our results indicate a lowering in particle size when either $\mathrm{Pr}$ or $\mathrm{Nd}$ is doped to a cerium doped cobalt aluminate $\left(D_{\text {DLS }}(\mathrm{Ce})=1621.6 \mathrm{~nm}, \quad D_{\text {XRD }}(\mathrm{Ce})=46.7 \mathrm{~nm}\right.$; $D_{\text {DLS }}(\mathrm{Ce}-\mathrm{Pr})=890.3 \mathrm{~nm}, \quad D_{\text {XRD }}(\mathrm{Ce}-\mathrm{Pr})=41 \mathrm{~nm}$; $\left.D_{\text {DLS }}(\mathrm{Ce}-\mathrm{Nd})=822 \mathrm{~nm}, \quad D_{\mathrm{XRD}}(\mathrm{Ce}-\mathrm{Nd})=36 \mathrm{~nm}\right)$.

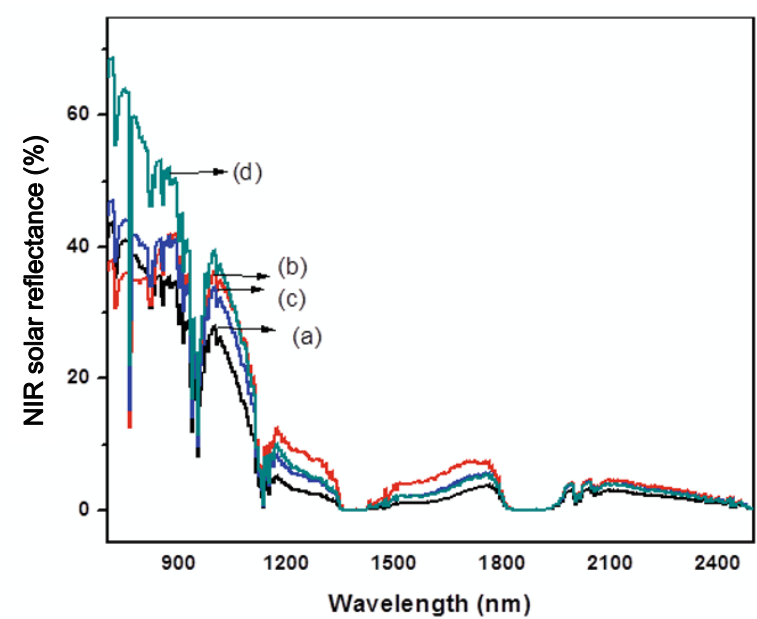

Fig. 4 Solar irradiance spectra of oxides (a) Al, $\mathrm{Cu}, \mathrm{Co}$; (b) Al, Cu, Co, Ce; (c) Al, Cu, Co, Ce, Pr and (d) Al, Cu, Co, Ce, $\mathrm{Nd}$. 
Morphological changes as demonstrated by orientation changes in the crystal structure of the $\mathrm{Nd}$ doped sample could then be considered as the cause for higher NIR reflectance from the sample.

As a prerequisite to evaluation of performance of the developed Ce-Nd pigment for various applications, bleed resistance on treatment with acid, alkali and water, oil absorption, light fastness and heat stability were evaluated. For acid and alkali resistance, the pigment was treated with $2 \% \mathrm{H}_{2} \mathrm{SO}_{4}$ and $2 \% \mathrm{NaOH}$ solution overnight. Subsequently, the pigment was washed with water, filtered, dried and color parameters determined. The $\mathrm{Ce}-\mathrm{Nd}$ pigment remained color fast in the presence of strong acids and bases. Bleed resistance of the pigment was carried out with water, mineral turpentine, and isopropyl alcohol, methanol, and ethanol etc. The pigments are non-migratory, and do not dissolve or bleed in contact with various solvents. The blue pigment shows excellent bleed résistance. The water soluble matter determined for the blue pigment was found to be $0.04 \%$ as per the procedure adopted by (ASTM D1208). Light fastness of the pigment carried out by irradiating the pigment for $6 \mathrm{~h}$ and the reading monitored for every one hour indicated a high level of stability. The salient observations from tests carried out as per ASTM D262 are reported in Table 2.

A paint formulation developed as per procedures adopted by standard paint manufacturers, employing long oil alkyd resin medium was coated on a checkered board with white and black surfaces to a thickness of $24 \mu \mathrm{m}$ using a K-coater. The color coordinates of $\mathrm{Nd}$ doped sample on white and black surfaces were similar with $\Delta E$ value of 5.32, thus indicating their potential to

Table 2 Test methods for rare earth doped blue pigment (Ce-Nd)

\begin{tabular}{ll}
\hline Test method & Observation \\
\hline Mass color (Description) & Grey-blue \\
Tint tone (Description) & Light blue \\
Moisture / Volatiles at $120{ }^{\circ} \mathrm{C}$ for $1 \mathrm{~h}$. & $0.12 \%$ \\
Sieve residue on 240 Mesh & $37.84 \%$ \\
Oil absorption & 44.08 \\
Water soluble matter & $0.04 \%$ \\
\hline \hline Bleed resistance & \\
\hline Water & 10 \\
Mineral turpentine & 10 \\
Iso propyl alcohol & 10 \\
Methanol & 10 \\
Ethanol & 10 \\
\hline
\end{tabular}

serve as colorants for surface coating applications.

In a similar manner, incorporating $7 \%$ of the pigment into PMMA produced uniform color distribution (Fig. 5). The color coordinates measured on three exposed surfaces of the disc produced were compared with each other and the $\Delta E$ value was below 2. It is clear that the pigment was uniformly dispersed into the matrix and produced more or less the same color that it possessed prior to dispersing into the plastic.

In essence, cobalt blue, an ideal inorganic pigment with blue hue and spinel structure has $\mathrm{Co}^{2+}$ and $\mathrm{Al}^{3+}$ ions occupying tetrahedral and octahedral positions. On doping with rare earth and transition metal ions like copper, the stable spinel structure remains intact differing only slightly in the size of the lattice. For instance, doping with a transition metal ion like $\mathrm{Cu}^{2+}$, at appropriate ratios, resulted in a mixed spinel with relative XRD reflection intensity of 0.6 , similar to that of cobalt aluminate. Doping with rare earth elements provides for shielding effect of $5 \mathrm{~s}$ and $5 \mathrm{p}$ energy levels, resulting in host independent optical properties. The band gap energy remained at $(2.4 \pm 0.2) \mathrm{eV}$, indicating that the color of the resultant oxide would remain blue. The same was confirmed from the absorbance bands at $540 \mathrm{~nm}, 578 \mathrm{~nm}$ and $627 \mathrm{~nm}$, which is characteristic of ${ }^{4} \mathrm{~A}_{2}(\mathrm{~F}) \rightarrow{ }^{4} \mathrm{~T}_{1}(\mathrm{P}) \quad \mathrm{Co}(\mathrm{II})$ transitions. CIELAB color coordinates are in concurrence to the above observation. One of the observed effects of rare earth doping was a reduction in size of the crystals and particles. Though literature suggests that NIR reflectance of a pigment can increase with a reduction in size, from our observations it can be concluded that the changes to the crystal size and/or crystal orientation on doping rare earth metal ions, more so

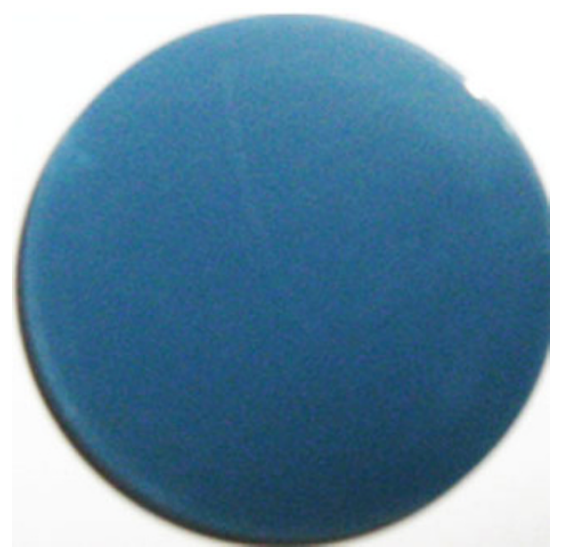

Fig. 5 Color profile of plastic containing blue colored pigment based on neodymium doped cobalt aluminate. 
with neodymium compared to praseodymium produced a blue colored pigment with almost $10 \%$ enhancement in NIR reflectance.

\section{Conclusions}

Through this work, a feasibility to enhance the performance characteristics of widely used pigments such as cobalt blue through appropriate doping with rare earth metal ions is reported. Properties such as NIR reflectance is improved through changes brought about to the crystal orientation by appropriate choice of rare earth doping. The prepared pigment had all properties such as chemical inertness and light fastness for its applications in exterior coatings, coloring of plastics and ceramics and leather.

\section{Acknowledgement}

One of the authors (SPR) thanks the Department of Science and Technology, Government of India for the funding received under the WOS-A program. Financial assistance of the CSIR New Delhi under the XII Plan project is also acknowledged. Authors also thank Dr. MLP Reddy and his team at NIIST, Thiruvananthapuram for their support in the characterization. The support of Dr. UV Varadaraju, IIT Madras, Chennai for useful discussions on the topic is acknowledged.

\section{References}

[1] Levinson R, Akbari H, Berdahl P, et al. A novel technique for the production of cool colored concrete tile and asphalt shingle roofing products. Sol Energy Mater Sol Cells 2010, 94: 946-954.

[2] Levinson R, Berdahl P, Akbari H. Solar spectral optical properties of pigments - Part II: Survey of common colorants. Sol Energy Mater Sol Cells 2005, 89: 351-389.

[3] Song JE, Kim YH, Kang YS. Preparation of indium tin oxide nanoparticles and their application to near IR-reflective film. Curr Appl Phys 2006, 6: 791-795.

[4] Thongkanluang T, Limsuwan P, Rakkwamsuk P. Preparation and application of high near-infrared reflective green pigment for ceramic tile roofs. Int $J$ Appl Ceram Technol 2011, 8: 1451-1458.

[5] Uemoto KL, Sato NMN, John VM. Estimating thermal performance of cool colored paints. Energ Buildings 2010, 42: 17-22.
[6] Levinson R, Berdahl P, Akbari H, et al. Methods of creating solar-reflective nonwhite surfaces and their application to residential roofing materials. Sol Energy Mater Sol Cells 2007, 91: 304-314.

[7] Jeevanandam P, Mulukutla RS, Phillips M, et al. Near infrared reflectance properties of metal oxide nanoparticles. J Phys Chem C 2007, 111: 1912-1928.

[8] Smith AE, Mizaguchi H, Delaney K, et al. $\mathrm{Mn}^{3+}$ in trigonal bipyramidal coordination: A new blue chromophore. $J$ Am Chem Soc 2009, 131: 17084-17086.

[9] Laha S, Sharma R, Bhat SV, et al. $\mathrm{Ba}_{3}\left(\mathrm{P}_{1-x} \mathrm{Mn}_{x} \mathrm{O}_{4}\right)_{2}$ : Blue/green inorganic materials based on Tetrahedral Mn(V). Bull Mater Sci 2011, 34: 1257-1262.

[10] Wang W, Xie Z, Liu G, et al. Fabrication of blue coloured zirconia ceramics via heterogeneous nucleation method. Cryst Growth Des 2009, 9: 4373-4377.

[11] Sreeram KJ, Aby CP, Nair BU. Synthesis and characterization of doped rare earth oxides for environmentally benign nontoxic reddish-yellow pigments. Chem Lett 2008, 37: 902-903.

[12] Li M, Yu XF, Yu WY, et al. Efficient and switchable manganese luminescence in $\mathrm{MnF}_{2}$ :Ce nanocrystals. $J$ Phys Chem C 2009, 113: 20271-20274.

[13] Li YC, Chang YH, Chang YS, et al. Luminescence and energy transfer properties of $\mathrm{Gd}^{3+}$ and $\mathrm{Tb}^{3+}$ in LaAlGe2O7. $J$ Phys Chem $C$ 2007, 111: 10682-10688.

[14] Li W, Lee J. Microwave assisted sol-gel synthesis and photoluminescence characterization of $\mathrm{LaPO}_{4}: \mathrm{Eu}^{3+}, \mathrm{Li}^{+}$nano phosphors. $J$ Phys Chem $C$ 2008,112: 11679-11684.

[15] Sreeram KJ, Aby CP, Nair BU, et al. Colored cool colorants based on rare earth metal ions. Sol Energy Mater Sol Cells 2008, 92: 1462-1467.

[16] Kar JK, Stevens R, Bowen CR. Rare earth cuprates for ceramic colouring application-An investigation. $J$ Alloys Compd 2008, 455: 121-129.

[17] Sarasamma VV, Lakshmipathi RM. Near-infrared reflecting inorganic pigments based on molybdenum and praseodymium doped yttrium cerate: Synthesis, characterization and optical properties. Sol Energy Mater Sol Cells 2011, 95: 2685-92.

[18] Zayat M, Levy D. Blue $\mathrm{CoAl}_{2} \mathrm{O}_{4}$ particles prepared by the sol-gel and citrate gel methods. Chem Mater 2000, 12: 2763-9. 
[19] Trinh TL, Nguyen NL, Le HH. Photoluminescence properties of Co-doped $\mathrm{ZnO}$ nanorods synthesized by hydrothermal method. J Phys D Appl Phys 2009, 42: 065412.

[20] Tandon SP, Gupta JP. Measurement of forbidden energy gap of semiconductors by diffuse reflectance technique. Phys Status Solidi 1970, 38: 363.

[21] Sarasamma VV, Sheethu J, Lakshmipathi RM. Novel environmental benign yellow inorganic pigments based on solid solutions of Samarium-transition metal mixed oxides. J Am Ceram Soc 2011, 94: 997-1001.

[22] Bamford CR. The application of the ligand field theory to coloured glasses. Phys Chem Glasses 1962, 3: 189.

[23] Volanti DP, Rosa ILV, Paris EC, et al. The role of the $\mathrm{Eu}^{3+}$ ions in structure and photoluminescence properties of $\mathrm{SrBi}_{2} \mathrm{Nb}_{2} \mathrm{O}_{9}$ powders. Opt Mat 2009, 31: 995. 